\title{
Inositol-Trisphosphate 3-Kinase B
}

National Cancer Institute

\section{Source}

National Cancer Institute. Inositol-Trisphosphate 3-Kinase B. NCI Thesaurus. Code C148586.

Inositol-trisphosphate 3-kinase B (946 aa, 102 kDa) is encoded by the human ITPKB gene. This protein plays a role in the conversion of inositol trisphosphate (IP3) to inositol tetrakisphosphate (IP4). 